duct where a vein or other tissue that has no natural inmunity against the chemical irritation of bile is used, we have the very conditions that produce a large anount of scar tissue, so subsequent contraction inevitably ensues.

The conclusion may be stated that repair of any structure over which irritating discharges flow should be made by tissues that are either wholly or partly immune to these discharges. Repair of defects of the common duct, then, should be done with a view to the avoidance of subsequent contraction which will surely occur, whether epithelium lines the newly constructed tube or not, if nonimmune tissues foreign to this region are used. It seems that the most satisfactory reconstruction occurs when the stump of the common or hepatic duct is sutured to the mobilized mucosa and submucosa of the duodenum. In this way epithelial and subepithelial layers of tissue that are accustomed to the biliary discharges are employed; and if an accurate approximation is made, the submucosa of the duodenum unites with the corresponding tissue of the stump of the duct, and no more contraction should occur than would talie place after suturing a wound in the intestine. Dr. William J. Mayo has employed such a technic in his clinic for a number of years, and similar work has recently been reported by $\mathrm{Dr}$. Le Grand Guerry.

\section{RECONSTRUCTION OF THE CHOLEDOCHUS}

\section{LE GRAND GUERRY, M.D. COLUMHL, S. C.}

Surgeons are occasionally forced to the necessity of reconstructing the conmon duct. Surgical literature is full of case reports, and many methods have been advocated by equally as many writers, involving the transplanting of fascia, the transplanting of blood vessels, the transplanting of the peritoneal layer of the duodenum, and so on to the end of the chapter. Some of the operations are good and others are distinctly bad.

Experimentally many plans have been tried on dogs with varying degrees of success. Unfortunately, what will work in the dog laboratory will not always work in the human abdomen, and the simple method 1 present, although done independently under the force of circumstances seven years ago at our hospital, is not an original plan, for in reviewing the literature I find case reports of almost the identical procedure. I do not wish the foregoing statement to be construed as a criticism of the invaluable experimental work carried on by Crile, Cushing, Horsley and many others, for we owe a large part of our progress in surgery to such work. I feel, however, that when due allowance has been made, there is a tendency among some to test the final value of a given method in the experimental laboratory rather than under actual conditions in the human body.

In January, 1916, Mayo ${ }^{1}$ published a splendid article on "Restoration of the Bile Passages," which every one interested in this subject should read. The method described in this article is almost identical in principle with the one under discussion. It appears to me that in our effort to find something new under the sun we have focused our thought too much on the experi-

1. Mayo, W. J.: Surg. Gynec. and Obst., 1916, R2, 1.6. mental laboratory and have overlooked the most natural way of overcoming these defects in the bile passages.

REASONS FOR RECONSTRUCTION

Some of the reasons why it is necessary to reconstruct the common duct are as follows:

1. In case of permanent obstruction at the head of the pancreas, if the gallbladder is intact, we shall have plain sailing. Cholecystoduodenostomy is, however, a short-circuiting operation rather than a reconstructing of the bile passages. If the gallbiadder has been removed, there will be another story to tell.

2. It may be necessary to restore the bile passages cin account of inflammatory stricture of the common duct. If the stricture of the common duct extends above the junction of the cystic and hepatic ducts, it may be necessary to excise the strictures and then, if possible, apply the method to be described, or the stricture may be divulsed.

3. The common duct may be divided in the operation of cholecystectomy. As a matter of fact, injuries to the choledochus are usually the result of operative measures. If the accident is discovered mmediately, repair is much easier than if a secondary operation is necessary to correct the injury. It is vitally necessary to remember here that the junction of the hepatic and cystic ducts which form the common duct is not always at a fixed point.

Whenever we attempt the operation of cholecystectomy, the point just mentioned must be constantly borne in mind. The usual position at which the cystic duct enters the hepatic duct is about three quarters of an inch below that portion of the hepatic duct which lies within the liver itself. However, the junction of these two ducts which form the common duct may occur as high up as the fissure of the liver, or they may run parallel with each other and unite almost at the entrance into the duodenum. According to Gray's Atratomy, they may remain independent throughout their course, or the junction may occis: at any point between the fissure of the liver and the duodenum.

Not only, then, do we have the junction of the hepatic duct and the cystic duct at a point whose location varies, but the two ducts ruming a parallel course and in intimate association one with the other and at times overlapping each other. When this unusual anatomic situation occurs, unless the two ducts are isolated and identified before the gallbladder is removed, accidental injury to the hepatic or common duct can and often does occur.

A case within the last few month beautifully illustrates this point. A male patient, aged almost 60 , had a large stone in the ampulla of Vater, prodicing obstruction of the common duct. The hepatic and cystic ducts were both distended to the size of one's index finger and could be clearly traced almost to the duodenum before the junction was effected.

\section{RESULTS OF OPERATION}

The three essential things to be accomplished by the operation are as follows:

1. In certain of the cases in which the duodenum is closely bound down by adhesions, its mobilization is most important, as we are thereby enabled to effect the anastomosis with greater accuracy.

2. This step I believe to be fundamentally necessary. The essential thing, as the illustration will show, 
is so to mobilize the mucosa of the duodenum that when the suture line is completed, the mucosa and the submucosa of the duodenum will be directly united to the light structures of the hepatic duct. If this is done, we shall have a continuous epithelial lined passage, and contraction in all probability will not occur. This point illustrates the inherent weakness in many of the so-called autoplastic reconstructions of the bile passages. Some of the methods break down just here, in that they fail to provide a continuous mucus lined passage for the bile.

3. The third objective to be attained is the one so clearly set forth by Dr. Horsley in the preceding paper. His experimental work shows clearly that contraction may occur in an epithelial lined sinus: "Construction is due to contraction of underlying fibrous or connective tissue and not to contraction of the epithelium itself"' (Horsley).

The absence of a proper submucosa as a covering for the line of union may bear the same relation to the contraction of the anastomosis as the corium does to a burn of the shin. We do not have contraction in a superficial burn of the skin, because the corium, which consists of connective tissue, that is, elastic fibers, contributes elasticity to the skin. This portion, also the seat of the sensitive layer, is not destroyed. On the other hand, however, contraction always occurs when the corium is destroyed. The point is that the corium bears the same relation to contraction following a burn of the skin as the submucosa bears to contraction folluwing anastomosis between the common duct and the duodenum.

\section{CONCLUSION}

I wish to make this point perfectly clear. I am not setting up the claim that this is the only way of remedying these defects in the bile passages. We may be quite sure that in many instances this method will not be suitable. What I do contend, however, is that the plan has a sound surgical and physiologic basis.

As the illustrations will show, the method provides a continuous mucus-lined passage and a submucosa from a location and under conditions as normal as we may hope to obtain. It appears to me, then, that in the group of cases suitable for this method of relie $\hat{f}$, the bile passages may be restored as nearly as possible to a normal condition.

Briefly then, my experience with reconstruction of the bile passages is confined to seven cases. One particularly interesting point about the third case was that the stump of the hepatic duct was so short that, try as I might, it was quite impossible to suture the duodenum to the hepatic duct. Consequently the gap between the two, which was about one-half inch in length, was bridged by a small rubber tube about the size of a No. 9 catheter. To my intense delight, the tube was passed about the fourteenth day, and, after a slight external drain of bile which lasted for about one month, this patient has remained well ever since.

There were two deaths in the seven cases. One death in a woman aged 70 was due to surgical shock and followed the operation within three or four hours. The second fatal case was due to postoperative pneumonia. One patient, who survived the operation and was alive four years afterward, had a small external biliary fistula that drained bile intermittently. Her health, however, was much improved, and since then she has passed from under my observation. 'The remaining four patients have remained well ever since the operation, and may fairly be regarded as complete symptomatic cures.

\section{ABSTRACT OF DISCUSSION}

ON PAPERS OF DRS. HORSLEY AND GUERRY

Dr. Arthur G. Sullivan, Madison, Wis.: I wonder if yols fully grasp the significance of Dr. Horsley's statements as regards the influence of a lining epithelium on duct contracture? The question is constantly raised as to whether the epithelium actually grows and eventually unites in the new-formed canal macle by my method. A sinus lined by epithelium is by no means insured against contraction. The old belief that epithelium itself would prevent contracture is not correct. Epithelium itself does not necessarily have any influence as regards kceping a duct patent, nor does its absence interfere with the discharge from a persistent biliary fistula. Do you ever worry that a persistent biliary fistula will close? Your chief worry is that it will not close. As long as there is obstruction so that the course of least resistance is for the bile to come outside, the bile will come outside, epithelium or no epithelium. You all have had experience with fecal and urinary fistulas and have worried considerably for fear they would stay open, although you knew full well that they were not lined by epithelium. As Dr. Horsley indicates, the character of the wall itself holds the secret as to whether a new-formed sinus will eventually contract, granting, of course, that there is a constant and regular discharge of bile through the sinus. The epithelium fully lined the new-formed ducts in my experimental work.

The various methods which have bcen proposed for bile duct repair have looked very well in the illustrations, but many of them cannot be utilized at all in the average case which requires duct reconstruction. The method portrayed by Dr. Guerry looks good, and it evidently has been successful; but to be candid, I can scarcely see that the end result of Dr. Guerry's operation, as indicated by his illustration, is at all different from Dr. W. J. Mayo's, in which he mobilizes the duodenum and sutures to it the divided hepaticus. $I$ do not want you to get the wrong impression of my faith in the rubber-tube method. If you are faced with a predicament in which there is no gallbladder and no opportunity to unite the hepatic duct directly to the duodenum, put in a rubber tube. and cover it with the tisstes near at hand. As Dr. Coffey has stated, those tissues probably lend themselves better to the rather irritating effect of the bile than do those of a transplant. If you will do this, your efforts may be successful.

Dr. C. N. Davis, Chicago: Dr. Horsley made mention of some experiments done by me some three years ago. We worked with fifty dogs and transplanted fascial flaps in an effort to repair the common duct. Our results were good and bad. In confirmation of what Dr. Sullivan has said, we found that the ducts made by fascial flaps were lined by epithelium. The great majority of our animals were lost because of stricture, not through the fascial tissue, but at a point where the duct had been cut across. We tried to obviate this stricture by cutting the duct in an oblique manner. But this seemed to have no effect whatever. A few of the animals survived, but the great majority died because of the constriction where the duct was cut. Two or three years ago a Chicago surgeon resected the common duct in doing a gallbladder operation. A drainage tube was put in and the patient allowed to drain. Some three or four months after that we put a tube in and reconstructed the common duct over a $T$-tube. The bile discharged through the long end of the $\mathrm{T}$-tube and discharged normally into the intestinal tract. The tube was left in place for six months and the patient gained weight. Everything went lovely. A few months later the tube was removed, and in a short time the patient's condition was as bad as before the operation. She was operated on again, and later the tube was taken out, with a like bad result. She was operated on a fourth time. A T-tube was put in, and the patient says. it will be removed only from her dead body.

Dr. L. L. McArthur, Chicago: I had not the advantage of the recent expcrimental research work on bile tract restoration 
when I met with my first case in 1907. Dr. Sullivan's article had not then been published, so I improvised a means of reconstructing a common duct which had been injured in the preceding operation. The patient, who suffered two or three years with icterts whenever his ;stula closed, but was relieved when it was open, desired something to be done. It was possible to find a dilated proximal common duct. The gallbladder had been removed at a former operation. Into this dilated common duct it was possible to introduce a rubber tube. There was no possibility in the cicatricial tissue which surrounded this field (he had had three previous operations) of finding the distal portion of it. So a pursestring suture was made in the duodenum at the point most closely lying to the proximal end of the common duct, and a tube introduced through an incision in the center of this area after a pursestring suture had been made in the common duct proximal end and a tube inserted. Reasoning that it was essential that that tube should come away not at once, but after some time, I did this: I turned back a cuff on the rubber tube about one-quarter of an inch, then turned that back again so that I had a round knob on the end of the tube about twice the size of the tube, narrowing its lumen, but permitting the bile to flow. With the proximal end in the common duct, it was easy to constrict the common duct, leaving. its mucosa attached so that it brought it close to the duodenum. I wanted the tube to come away, but not too soon. I made it 8 inches long and let the 8 inches go down the duodenum, so that the constant peristaltic pulling for five or six weeks all that time gave a chance for epithelium to develop. That scheme works. I have done it now for the fourth time, and one of my associates, calling me to assist him in a difficult icteric case, repeated it successfully for the fifth time. The practical hint is. to follow the suggestion of Willy Meyer, bring the duodenum as close as possible to the stump of the proximal end of the common duct and keep it patulous until the mucosa can grow to mucosa. While the experience of any of us will not be great in numbers, so simple a resource as that described can be found in any operating room.

Dr. I. J. STrauss, Chicago: In 1912, when I reconstructed ureters from the fascia lata, I got a patent ureter. Epithelium will grow on any medium. You cannot prevent epithelium from growing over a hollow viscus. As to end results, experimentally from the bile duct work, success is due entirely to technical skill. If you take a fascial transplant uppermost, then the hydrostatic bile will distend the tube. Dr. Davis is correct. When I did ureteral work I did bile operations and put a stone into the duct. Then the hydrostatic action caused stricture, and you take out the stone and you have no stricture whatever. This shows that the bile within the common duct is under a very low pressure, and consequently there is always a constriction. If we have high hydrostatic action, we would have no pressure, and these cases of reconstruction of the bile duct would be a success.

Dr. J. Shelton Horsley, Richmond, Va.: The pathology of a biliary fistulous tract is intimately connected with such reconstructive work. Of course, the fistulas that do not close impress us. What is the proportion of external biliary fistulas that do not close to those that do? Exceedingly small. If they io not close we know the reason; usually some obstruction to the bile lower down. The Sullivan operation is as much a transplantation as when a vein or fascia is used and has the advantage of a pedicle for bland supply. Sullivan's procedure has the additional advantage. too, of using tissue in the neighborhood, which has some immunity to the irritating effects of the biliary discharges; but a free transplant is not so well nourished, has no immunity to the irritating discharges, and will eventually contract. The ideal method is to unite the stump of the duct to the submucosa of the duodenum. Dr. Sullivan has authorized me to say that he is in no way responsible for the T-tube. In pulling it out it causes too much damage.

Teach Health to the Children.-Since 90 per cent. of our American children leave school at or before the eighth grade, public health must be taught in the grades if the majority of the population is to be reached.-Minnesota Public Hcalth Assoriation Journal.
HEMOPHILIA

EXPERIMENTAL DATA BEARING ON THE EFFECT OF GLYCERINIZED EXTRACTS OF VISCERAL HEMOPHILIC TISSUE ON THE COAGULATION TIME OF BLOOD *

HARRY 'LOWENBURG, A.M., M.D.

A. I. RUBENSTONE, M.D. PHILADELPHIA

Inasmuch as the active etiology of hemophilia remains one of the unsolved mysteries of medicine. and inasmuch as medical science affords us no remedial agent which will permanently eradicate the disease, the investigations to be recorded were undertaken with the hope that some new information with reference to the cause of the remarkably slow coagulative property of the blood in hemophilia might be provided. The opportunity to conduct these investigations came to us by reason of the death of a 6 year old lad, who presented the classical family history of this disheartening affection. He had been admitted to the pediatric service of the Mount Sinai Hospital of Philadelphia on several occasions. Each time profuse hemorrhage had followed the slightest trauma to skin or mucosa. Usually he bled from the tongue, mouth or lips-the result of teeth bites from falls. The slightest pressure would produce extensive subcutaneous ecchymoses. At no time would the bleeding cease spontaneously or by the use of ordinary measures. Horse serum or the direct injection subcutaneously of freshly drawn human blood was always necessary to control the bleeding. The anemia following one of these attacks was always profound, and frequently he would become highly toxic following an injection, presenting hyperpyrexia, delirium, urticaria and other evidences of the intracirculatory destruction of foreign protein. Once the bleeding ceased, however. his color and animation would return with amazing rapidity. His father did not bleed, nor did his mother. nor his sister, but his brother, who even now is a patient under the care of one of us (Lowenburg) at the Mount Sinai Hospital, just recovering from a severe hemorrhage following a slight trauma on the forehead, and which required intravenous transfusion to control it, frequently has attacks of bleeding. There is no history of consanguinity. His maternal uncle is a bleeder, having required intravenous transfusion to control what appeared to be spontaneous hematuria. This occurred on two occasions and almost cost the patient his life. Another maternal uncle bled to death. Thus it is seen that we are dealing with a typically classical case of hemophilia. Our patient died at the Mount Sinai Hospital following uncontrollable intestinal hemorrhage of unknown origin.

Assuming that the blood of hemophiliacs does not come in contact with extravascular tissues (skin, muscle, fascia, etc.), that the coagulation time under such circumstances is unduly prolonged beyond normal is not the subject of professional controversy. Howell's experiment, wherein he showed that hemophilic blood drawn directly into a test tube sometimes consumes five hours in clotting, may be readily verified by repetition. Normal blood is coagulated within from thirty

* Read before the Section on Diseases of Children at the Sixty-Nintil Annual Session of the American Medical Association, Chicago. June, 1918. 